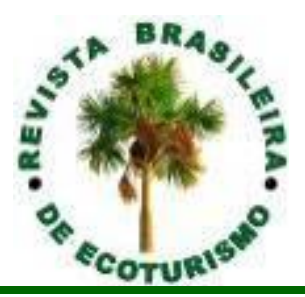

\title{
A demanda turística do Parque Estadual do Jalapão (PEJ, TO, Brasil) baseada em comentários de redes sociais
}

\section{The tourist demand of the Jalapão state park (PEJ, TO, Brazil) based on network social comments}

\author{
Maria de Fatima de Albuquerque Caracristi, José Elmar Feger, \\ João Eugenio Marynowski, Sarah Marroni Minasi
}

\begin{abstract}
RESUMO: Este artigo tem o objetivo de caracterizar a demanda para o destino turístico Jalapão a partir de dados extraídos de plataforma digital. Oferta e demanda são elementos essenciais nos negócios que envolvem a atividade turística. Isso porque o turismo é um complexo de serviços estruturalmente dispostos e constituídos como produto para atender aos diversos segmentos que se caracterizam pelos diferentes gostos e interesses. A quantidade demandada depende de variáveis que influenciam a escolha do consumidor: o preço, a renda, as motivações dos viajantes. O alvo desta investigação é a demanda real, aqueles que efetivamente consumiram o destino turístico Jalapão e registraram suas impressões nos comentários do TripAdvisor. Foram analisados os comentários considerando a localização, escolaridade, nível de renda e índice de urbanização. Os dados obtidos corroboram com o pressuposto de que a procedência do turista para o destino turístico Jalapão advém de locais com alta concentração de população urbana, renda e educação. A exceção é o estado do Tocantins que não apresenta os mesmos índices, mas por ser o Estado onde o Jalapão se insere, justifica a inserção como de maior recepção de turistas. Adicionalmente, as análises permitiram identificar um aumento crescente da demanda turística para o Jalapão, motivado principalmente pelos aspectos da paisagem e da natureza, dentre os quais se destacam as cachoeiras.
\end{abstract}

PALAVRAS-CHAVE: Demanda Turística; Destino Turístico; Parque Estadual do Jalapão; Ecoturismo.

ABSTRACT: This paper aims to characterize the demand for the tourist destination Jalapão from data extracted from the TripAdvisor platform. The target of the investigation is the real defendant, those who effectively consumed the tourist destination Jalapão. Supply and demand are essential elements in business involving tourism. This is because tourism is a complex of services structurally arranged and constituted as a product to serve different segments that are characterized by different tastes and interests. The quantity demanded depends on variables that influence the consumer's choice: the price, the income, the motivations of the travelers. Considering these aspects, the analyzes allowed us to understand that there is a growing increase in the tourist demand for Jalapão, motivated mainly by the aspects of the landscape and nature, among which the waterfalls stand out. All the data obtained corroborate to prove the hypothesis that the tourist origin for the tourist destination Jalapão comes from places with a high concentration of urban population and income.

KEYWORDS: Tourist Demand; Tourist Destination; Jalapão State Park; Ecotourism.

Sociedade Brasileira de Ecoturismo. Rua Dona Avelina, 225, Vila Mariana, São Paulo, SP - Brasil

291 E-mail: zneiman@gmail.com; Tel. (55-11) 99195-7685. 


\section{Introdução}

O desenvolvimento e a sustentabilidade dos destinos turísticos estão inexoravelmente relacionados ao planejamento territorial dos locais onde a atividade se consolida. O turismo desencadeia uma energia motriz que estimula todos os setores da economia, a ponto de autores o definirem como uma indústria (SESSA, 1983). Entretanto, o turismo insere-se no setor de serviços constituindo-se num conjunto de elementos que ensejam o seu funcionamento. Diante disso, a atividade se constitui num complexo processo efetuado por distintos componentes por ela abrangidos, dentre eles, a hospedagem, a alimentação, o lazer, a informação turística, o entretenimento, dentre outras variáveis (BENI, 2019). Nesse sentido, do lado da oferta, os serviços turísticos não se constituem em um produto estático, e sim, estão em constante evolução (COELHO; RIBEIRO, 2007). Da mesma forma, pelo ângulo da demanda, essa evolução transcorre no consumidor, visto que ele busca muito além de produtos/serviços turísticos. O viajante almeja por novas experiências, alterando assim, gostos e preferências referentes à demanda anterior (BENI, 2004; COELHO ; RIBEIRO, 2007).

Mediante esta conjuntura e a fim de contribuir para o entendimento do desenvolvimento de espaços que se apoiam na atividade turística, neste estudo procura-se responder ao seguinte questionamento: a urbanidade é uma característica responsável pela emissão de turistas para espaços com apelo ecológico, caso do Jalapão, no cerrado do Tocantins?

A escolha de parte desse estado da federação brasileira como abrangência para a pesquisa, se justifica porque o Tocantins é um espaço com forte motivação para o ecoturismo, a iniciar pela etimologia do próprio nome, Tocantins, de origem tupi, significa bico de tucano. Além disso, faz referência ao segundo maior rio totalmente brasileiro, o rio Tocantins, com 2 mil km de extensão, perde apenas para o rio São Francisco (ANA, 2020). Em conjunto com o rio Araguaia compreende uma das principais bacias hidrográficas do centro-oeste, a Araguaia-Tocantins, correspondendo a $10,8 \%$ do território brasileiro. Na referida Região, estão presentes os biomas Floresta Amazônica, ao norte e noroeste, e Cerrado nas demais áreas. Dadas as particularidades antes descritas, o estado possui grande potencial turístico: pesca esportiva, turismo ecológico, praias fluviais, a maior ilha fluvial do mundo (Ilha do Bananal), o polo turístico de Belém, o Parque Estadual do Jalapão (TO) e o Parque Nacional da Chapada dos Veadeiros (GO), reconhecido pelas cachoeiras (ANA, 2020).

As características naturais do Tocantins fundamentam a sua escolha como campo de pesquisa, visto que, desafiam as políticas públicas a impulsionarem a atividade turística como uma forte aliada para geração de emprego e renda. O turismo exige uma sinergia entre vários setores cuja interação com o meio ambiente às vezes se dá sob críticas ambientalistas porque são áreas de grande fragilidade. Envolve, demandas motivadas por diversos elementos, além da natureza, como aspectos culturais, históricos e motivações particulares que podem se materializar no ecoturismo, um segmento do mercado evidenciado nesta pesquisa. O Estado do Tocantins se constitui em uma diversidade ecossistêmica propícia para o Ecoturismo e Turismo de Aventura, localizado estrategicamente no espaço que se define 
como Amazônia Legal. Nesse território as atividades turísticas são frequentemente motivadas pelo turismo de lazer, especialmente no segmento de turismo de aventura, que se consolida gradativamente, principalmente na região do Jalapão.

O turismo é uma importante atividade econômica para o Estado do Tocantins no que diz respeito à geração de divisas e promoção de novas fontes de trabalho e geração de renda. $O$ setor de serviços, em que 0 turismo se coloca, contribuiu com um saldo de $74 \%$ no Produto Interno Bruto no Tocantins no ano de 2016, maior do que a agropecuária $(12,7 \%)$ e a indústria (13,3\%) (TO, 2017).

A investigação busca elucidar as características da demanda de turistas para o destino Jalapão, visando contribuir para a compreensão sobre as opções de ocupação deste espaço turístico, que é protegido por reservas de proteção integral e de uso sustentável. Abordar esse tema adotando como recorte espacial o Parque Estadual do Jalapão (PEJ) onde estão os mais visitados atrativos turísticos, se constitui uma contribuição acadêmica que reverbera em reflexões que podem servir para tomada de decisões relacionadas às políticas públicas que urgem por alcançar a sustentabilidade.

Para obtenção dos dados, utilizou-se como fonte a plataforma Tripadvisor (tripadvisor.com.br), que se constitui em um site de viagens com informações e opiniões relacionadas ao turismo. Segundo o administrador do site são compartilhadas 290 novas contribuições por minuto, o que o torna um campo de conteúdo interessante para investigações acerca do comportamento do consumidor como já apontado por Manosso, (2015); Cohen et. al, (2016). A partir desse entendimento vários autores se utilizam desta plataforma como fonte de dados para suas investigações (SANTOS et al., 2018; GUISSONI et al., 2019; FERNANDES et al., 2020).

O objetivo da pesquisa é caracterizar a demanda turística do Parque Estadual do Jalapão - PEJ com base em dados obtidos junto ao TripAdvisor. Como objetivos específicos, pretende-se: i) Identificar os principais locais de origem nacional e internacional de turistas do PEJ; ii) verificar as características socioeconômicas dos turistas identificados na plataforma digital; iii) analisar as características demográficas dos locais de origem dos turistas à luz dos conceitos de demanda turística para destinos ecológicos.

A pesquisa parte da premissa que a demanda turística para o Jalapão, seja ela interna ou externa, se caracteriza por viajantes provenientes de municípios com alta concentração de população urbana, que buscam agregar-se a espaços que possuam a natureza preservada. $O$ método de investigação é o dedutivo, com procedimentos de tratamento de dados próprios da pesquisa quali-quantitativa. Os dados analisados são provenientes de fontes bibliográficas e documentais. Quanto aos objetivos, classifica-se como um estudo exploratório - descritivo - analítico.

Para efeitos de organização textual, o artigo se inicia com esta introdução, seguido de uma seção que trata do referencial teórico. $\mathrm{Na}$ sequência, outra parte situa o turismo no Estado do Tocantins, prosseguindo com um tópico que trata da metodologia. Em seguida, tem-se a apresentação e discussão dos dados e encerra-se com as considerações finais. 


\section{Fundamentação teórica}

\section{Considerações sobre concentração populacional e Ecoturismo}

Martine (2007) argumenta que a urbanização constitui uma das forças mais relevantes no âmbito do século XXI, alertando para a necessidade de reconhecer que o maior crescimento urbano ainda está por vir. A proporção deve subir de patamares próximos a metade dos atuais 6,7 bilhões de habitantes do planeta que vivem em áreas urbanas, para $60 \%$ até 2030 (MARTINE, 2007). Mediante a isso, o autor enfatiza que o ritmo de crescimento das cidades ocorrido ao longo da história até os dias atuais está prestes a duplicar em pouco mais de uma geração (MARTINE, 2007)

As informações de Martine (2007) são relevantes na medida em que prevê que grande parte dessa população, que reside em áreas de concentração urbana tem no turismo em áreas naturais uma fuga para mitigar os efeitos negativos que a aglomeração desencadeia nos indivíduos que residem em determinadas cidades. No Brasil, pesquisa realizada no ano de 2010, verificou que o principal motivo de viagem para os que buscavam áreas naturais para realizar turismo era fugir do cotidiano urbano, da correria, do trabalho, do estresse e da violência, por meio de praticar alguma atividade diferente das rotineiras, a exemplo das atividades em meio à natureza (ABETA, 2010). Tais dados são referências importantes e podem contribuir para a elaboração de estratégia de desenvolvimento do turismo em áreas naturais.

As cidades com grande concentração urbana tornam-se núcleos potencializados pelas estruturas atuais de desenvolvimento. A maior parte dos incrementos econômicos provém das áreas urbanas, tornando-as 0 principal foco das interações entre população e meio ambiente afetadas pelo desenvolvimento (MARTINE, 2007). Ao mesmo tempo, os destinos de ecoturismo são escape para a população de habitantes que residem nesses núcleos de aglomeração, seja para diminuir o estresse ou a ambientação de espaço diferente do convencional

A análise da concentração urbana é um aspecto importante, visto que, dentre os fatores socioeconômicos de grande relevância para o turismo está a renda (RABAHY, 2003; 2020). Estas constatações, no contexto econômico mais amplo, são consideráveis, visto que caso o consumidor possua restrição orçamentária, leva em consideração os preços dos produtos a consumir, devido a relação direta com a sua renda. Assim, a escolha do consumidor, envolve a decisão sobre qual produto adquirir, considerando as suas preferências e restrição orçamentária (PINDYCK; RUBINFELD, 2002). Em estudo empírico realizado para verificar os fatores explicativos da demanda, Castro (2020) identificou que a renda média do local de origem do turista é estatisticamente relevante para os destinos paranaenses.

Alguns estudos sobre demanda em áreas de ecoturismo, como o desenvolvido por Vieira et al., (2014) identificou que o segmento de ecoturismo em Diamantina tem grande potencial; haja vista a presença de inúmeros atrativos naturais no município. Contudo, faltam entidades que se 
envolvam e participem do processo de desenvolvimento do ecoturismo, de maneira a dar solidez às necessidades intrínsecas a este tipo de atrativo naquele destino.

O turismo se caracteriza como o montante de atividades econômicas que possibilitam um conjunto de experiências que ocorrem fora do lugar habitual de residência ou de trabalho dos indivíduos (VALLS, 1996). Para irromper tais experiências é necessário existir unidades de produção de serviços que sejam capazes de combinar os elementos tangíveis e intangíveis dos negócios turísticos (VALLS, 1996).

Essa performance ocorre em um espaço geográfico, denominado destino turístico. O destino se constitui no resultado do efeito social, econômico e cultural decorrente do deslocamento das pessoas para locais que reúnem as condições para satisfazer as diferentes motivações turísticas (IVARS, 2003). Nesse sentido, nos citados espaços ocorrem as trocas do mercado turístico, principalmente a partir de duas variáveis: oferta e demanda (MANKIW,1999).

Historicamente, o turismo é estudado a partir desses dois elementos, que são interdependentes. Assim, mensurar o fluxo de turistas, o gasto médio, o tempo de permanência na cidade, seu perfil de viagem, bem como, o seu nível de satisfação, passou a ser trivial na elaboração de estratégias de promoção e venda dos destinos turísticos (BOULLÓN, 2002; RABAHY, 2003).

Um aspecto interessante que pode definir a demanda turística está correlacionado com a motivação, aquilo que leva os indivíduos a selecionarem, num universo de possibilidades de viagens, aquela do interesse (HIRATA; BRAGA, 2017). Abordando o tema a partir de diferentes perspectivas as autoras reiteram a importância de se estudar a motivação de viagem, alegando que "embora a análise sistemática de fatores socioeconômicos e demográficos da demanda [...] seja importante, ela se torna ainda mais relevante quando conjugada a uma análise dos indivíduos que a compõe". (HIRATA; BRAGA, 2017, p. 17).

A análise da distribuição dos fluxos turísticos também tem sido o foco de investigações acadêmicas. Assim, o controle da atividade turística é muito importante para se conter os avanços indesejados e manter preservados os destinos mais procurados. Para se assegurar a qualidade, requer "a ação efetiva do Estado na criação de condições materiais (os sistemas de engenharia) e não materiais (as normas) para 0 desenvolvimento da atividade turística no país" (CRUZ, 2005. p.33).

Nos anos 1980 o termo desenvolvimento sustentável passou a ser usado em conjunto com turismo e surgem novos conceitos no meio turístico como turismo sustentável, ecoturismo, capacidade de carga. O que se buscava eram alternativas da exploração turística, mais respeito às fragilidades ambientais e, nesse sentido, o turismo alternativo passa a ser a resposta a uma efervescência de novos hábitos que se consolidam no que se convencionou a chamar de pós-modernidade.

Os conceitos preteritamente discutidos foram incorporados à política pública nacional. Na publicação intitulada Diretrizes para uma Política 
Nacional de Ecoturismo (MTUR, 2010), o "Ecoturismo", corresponde a um segmento da atividade turística que utiliza, de forma sustentável, o patrimônio natural e cultural, incentiva a conservação e busca a formação de uma consciência ambientalista por meio da interpretação do ambiente, promovendo o bem-estar das populações.

Entre diversas interpretações e definições para Ecoturismo, a conceituação estabelecida continua sendo referência no País. A Sociedade Internacional de Ecoturismo (TIES) apresenta conceito semelhante: "Ecoturismo é uma viagem responsável a áreas naturais, visando preservar o meio ambiente e promover o bem-estar da população local' (ABETA, 2010, $\mathrm{s} / \mathrm{p})$.

Já no que diz respeito ao Turismo de Aventura o conceito fundamenta-se em aspectos que se referem à atividade turística e ao território em relação à motivação do turista, e pressupõe o respeito nas relações institucionais, de mercado, entre os praticantes e com o ambiente. "No turismo de aventura os movimentos turísticos são entendidos como deslocamentos e estadas que pressupõem a efetivação de atividades motivadas pela prática de esportes de aventura não competitivas, que dão consistência a este segmento, e envolvem a oferta de serviços, equipamentos e produtos em função da atividade turística" (DANTAS;PIRES, 2015).

Os fluxos turísticos que se destinam a localidades com apelo ao ambiente natural, cada vez mais se intensificam e não ocorre apenas no âmbito do ecoturismo ou turismo de aventura, se ampliam nas comunidades indígenas, no âmbito do turismo cultural e étnico.

\section{Demanda turística em áreas de preservação}

O Instituto Chico Mendes (ICMbio) registra que, enquanto o turismo no geral avança $7,5 \%$ ao ano, a prática de ecoturismo cresce cerca de $20 \%$. No Brasil, mais de um milhão de viajantes geram um faturamento de US $\$ 70$ milhões para o segmento. Segundo os dados de visitação em Unidades de Conservação (UCs) federais do ICMBio, em 2018, os parques nacionais tiveram um aumento na visitação de $6,15 \%$, com um total de 12,4 milhões de visitas, sendo que, em 2017, tinha sido 10,7 milhões de visitas (ICMBio, 2020).

A pesquisa de receptivo internacional brasileiro do ano de 2018 mostra que houve uma entrada de 6,6 milhões de turistas no país, esses são provenientes da América do Sul (61,2\%); da América do Norte $(10,4 \%)$, da Europa (22,1\%), juntos contabilizam 94\%, e chegam via aérea $(65,4 \%)$ e terrestre (3,15\%) (MTUR, 2018).

Essas informações mostram a importância que os estudos de indicadores têm para elaborar políticas de destinos turísticos ecológicos, ainda satisfatórias no Brasil. Os pesquisadores Lacerda, et al. (2019) ao analisarem os sistemas de indicadores de sustentabilidade adaptados e elaborados para atividade turística, encontraram que a maioria dos sistemas não contempla todas as dimensões que sofrem impacto com a atividade 
turística como: social, ambiental, cultural, política institucional e econômica, dentre outras, também diz que os indicadores não apresentam as dimensões de serviços turísticos e infraestrutura turística. Além disso, os autores alegam que são elaborados a partir de valores globais ou adaptados de outras regiões e na sua aplicação não considera a participação dos atores sociais.

Para evitar a degradação do ambiente em unidades de conservação, há a necessidade de elaborar os planos de manejo. No Brasil, a Lei № 9.985/2000 estabelece as bases para a elaboração de planos de manejo no âmbito do Sistema Nacional de Unidades de Conservação. Neste diploma legal a definição de Plano de Manejo corresponde a um documento técnico mediante o qual, com fundamento nos objetivos gerais de uma Unidade de Conservação, se estabelece o seu zoneamento e as normas que devem presidir o uso da área e o manejo dos recursos naturais.

As unidades de conservação devem dispor de um Plano de Manejo que abranja a área da Unidade de Conservação, sua zona de amortecimento e os corredores ecológicos, incluindo medidas com o fim de promover sua integração à vida econômica social das comunidades vizinhas (Art. 27, §1ํㅡㄴ Lei N. 9985/2000; ICMBio, 2020).

Dado o interesse da presente investigação, discute-se neste espaço alguns aspectos relacionados com o Plano de Manejo do Parque Estadual do Jalapão (TO, 2003) e seus reflexos no turismo. Observa-se que o Plano de manejo do Parque Estadual do Jalapão traz algumas poucas indicações ao funcionamento da atividade turística nos seguintes itens constantes no Quadro 1.

Quadro 1: Referências à turismo no Plano de Manejo do PEJ.

Frame 1: References to tourism in the PEJ management plan.

\begin{tabular}{|l|l|}
\hline \multicolumn{1}{|c|}{ Item do plano } & Referência \\
\hline $\begin{array}{l}\text { Gestionar junto ao Conselho Consultivo do Parque a criação de } \\
\text { instância executiva articuladora, captadora e impulsionadora das } \\
\text { atividades turísticas e recreativas no Jalapão. Esta instância deverá } \\
\text { ser criada na forma de instituto ou agência articuladora de } \\
\text { desenvolvimento local, instituída como OSCIP (Organização da } \\
\text { Sociedade Civil de Interesse Público). }\end{array}$ & TO (2003), p. 57 \\
\hline $\begin{array}{l}\text { Incentivar o cooperativismo e associativismo para o desenvolvimento, } \\
\text { melhoria e aproveitamento das oportunidades oferecidas pelo PEJ. }\end{array}$ & TO (2003), p. 61 \\
\hline $\begin{array}{l}\text { Realizar estudos sobre a viabilidade de implementação de novos } \\
\text { empreendimentos ecoturísticos e de turismo rural, dentre outras } \\
\text { categorias, nos municípios da Zona de Amortecimento. }\end{array}$ & TO (2003), p. 61 \\
\hline $\begin{array}{l}\text { Adequar a sede da Fazenda Triagro como Centro de Apoio à } \\
\text { fiscalização, ao turismo e à pesquisa no PEJ. }\end{array}$ & TO (2003), p. 61 \\
\hline $\begin{array}{l}\text { Maior interação e engajamento das comunidades nas ações de } \\
\text { proteção e uso público do PEJ. }\end{array}$ & $\begin{array}{l}\text { TO } \\
\text { Encarte } \\
\text { Planejamento }\end{array}$ \\
\hline $\begin{array}{l}\text { Permitir o desenvolvimento socioeconômico sustentável das } \\
\text { populações tradicionais por meio do artesanato e da prestação de } \\
\text { serviços turísticos. }\end{array}$ & $\begin{array}{l}\text { TO } \\
\text { Encarte } \\
\text { Planejamento }\end{array}$ \\
\hline
\end{tabular}

Fonte: Elaboração dos autores com base em (TO, 2003).

Source: elaborated by the authors based on (TO, 2003). 
O plano de manejo é um instrumento que deve estar à disposição dos gestores e operadores do ecoturismo, visto que são importantes para que os fluxos turísticos sejam operados com segurança, com foco na demanda, mas respeitando os limites de sobrevivência dos espaços sócioambientais.

\section{Jalapão: objeto de estudo}

O território turístico Jalapão localizado no Estado do Tocantins é caracterizado por atrair uma demanda vocacionada ao turismo de aventura ou que pratica o turismo ecológico. O Jalapão remete a uma área de aproximadamente $34 \mathrm{mil} \mathrm{km}^{2}$, envolvendo oito municípios tocantinenses: Lagoa do Tocantins, Lizarda, Mateiros, Novo Acordo, Ponte Alta do Tocantins, Santa Tereza do Tocantins e São Félix do Tocantins (TO, 2020). Localiza-se nas divisas entre os Estados do Tocantins, Piauí, Maranhão e Bahia, e tem seu bioma protegido por cinco unidades de conservação e proteção integral: a Estação Ecológica Serra Geral do Tocantins, a Estação Ecológica do Rio Preto, o Monumento Natural Canyons e Corredeiras do Rio Sono, o Parque Estadual do Jalapão (PEJ), e o Parque Nacional das Nascentes do Rio Parnaíba, representando o maior conjunto de unidades de conservação de proteção integral de todo o Cerrado (ICMBio, 2013).

A região conhecida como Encantos do Jalapão é um destino que recebe uma demanda crescente de turistas. A maioria dos atrativos está localizado nos municípios de Mateiros, Novo Acordo, Ponte Alta do Tocantins e São Félix do Tocantins. Em meio a $34 \mathrm{mil} \mathrm{km}^{2}$ de paisagem árida, a região é cortada por rios, riachos e ribeirões, todos de águas transparentes e potáveis.

O Jalapão é ideal para a prática de esportes, entre eles o rafting, a canoagem, o rapel e as trilhas a pé e de bicicleta. Entre os atrativos mais procurados estão a Cachoeira da Velha, uma enorme queda d'água em forma de ferradura de aproximadamente 100 metros de largura e 15 metros de altura; as Dunas, cartão postal do Jalapão, composto por areias finas e alaranjadas que chegam a 40 metros de altura; os Povoados do Mumbuca e Prata, comunidades remanescentes de quilombos, a Serra do Espírito Santo, formação rochosa onde é possível apreciar a flora da região; a Cachoeira do Formiga, uma encantadora nascente de água verdeesmeralda; e os Fervedouros, com suas águas transparentes, nas quais é impossível afundar.

A preocupação em manter a preservação da área é representada pela presença do Parque Estadual do Jalapão, o Parque Nacional das Nascentes do Rio Parnaíba; a Estação Ecológica da Serra Geral do Tocantins; a Área de Preservação Ambiental (APA) Serra da Tabatinga; e a Área de Proteção Ambiental (APA) Jalapão.

A atividade turística se revela um importante recurso para otimizar a economia e impulsionar o desenvolvimento local, é estimulante para o município de Mateiros, que tem a soja como fonte produtiva mais significativa. A população está dividida em $82 \%$ em nível de pobreza; 
$57,01 \%$ na faixa de pobreza absoluta e $30,22 \%$ em extrema pobreza. Os domicílios apresentam rendimentos mensais com até meio salário-mínimo por pessoa, representa $45.2 \%$ da população nessas condições, o que o colocava na posição 70 de 139 dentre as cidades do estado e na posição 2125 de 5570 dentre as cidades do Brasil (IBGE, 2016; TO, 2020).

A pesquisa de Dutra e Aquino (2018) realizada para identificar uma maneira ideal de monitoramento turístico para o Jalapão, evidenciou o nível de satisfação do público-alvo com o turismo local, por meio da avaliação de itens-chave que são considerados primordiais para o desenvolvimento de uma destinação turística. Por meio dos resultados evidenciados por esses indicadores, pode ser constatada a necessidade de criação de uma política pública de turismo no município de Mateiros que priorize ações voltadas para a educação, no que diz respeito à formação profissional na área de turismo.

\section{Metodologia}

O presente estudo visa interpretar a característica da demanda turística a partir de dados extraídos da plataforma TripAdvisor. Partiu-se da premissa de que a demanda turística para o Jalapão, seja ela interna ou externa, se caracteriza por viajantes provenientes de municípios com alta concentração de população urbana, que buscam agregar-se aos espaços que possuam a natureza preservada.

A coleta de dados foi realizada considerando o espaço temporal a partir de 2012, quando foi compartilhado o primeiro comentário no Tripadvisor. O procedimento para operacionalizar a coleta das informações foram: i) aquisição dos dados dos comentários no site TripAdvisor; ii) préprocessamento e tabulação das origens das pessoas que comentaram a viagem; iii) elaboração de tabela com todos os locais de origem nacionais e internacionais; iv) geração de mapas com dados dos turistas quanto: origem/distância, renda, urbanização e nível educacional.

A coleta dos comentários ocorreu usando técnicas de captura automatizada de dados (web scraping) (MUNZERT et al., 2014). O resultado deste passo foi um conjunto de documentos com 2.104 comentários feitos para os atrativos mais visitados e recomendados pelo Tripadvisor para 0 PEJ. Após, os locais de origem foram identificados e complementados/corrigidos manualmente os locais que apresentavam erro, como falta de informação e preenchimento trocado (estado no lugar de cidade, p.ex.). Os dados demográficos obtidos sobre os locais de origem são auxiliares na configuração da caracterização da demanda turística do Jalapão e foram trabalhados posteriormente relacionando-os com as premissas teóricas.

As informações sobre a origem dos turistas para o destino turístico Jalapão (TO) foram agrupadas em turistas nacionais e internacionais. No caso de turistas nacionais, foram compilados por estados, e para turistas internacionais, por países. Os dados então foram inseridos em um Sistema de Informações Geográficas (SIG) com o software Quantum GIS - QGIS. 
A fim de caracterizar a demanda para o PEJ, foram definidas as seguintes variáveis: quantidade (volume) de turistas, fluxo dos turistas, distância da procedência, rendimento domiciliar per capita, média de anos de escolaridade, e distribuição da população urbana. A fim de representar essas variáveis, o processamento dos dados também classificou em um gradiente as camadas dos estados e países de acordo com dados sociodemográficos secundários.

Com a ferramenta de classificação da tabela de atributos foram processados os dados para representar o volume de comentários. Para demonstrar o volume de turistas de acordo com o estado ou país de origem foi utilizada a representação por círculo proporcional. Nessa opção o atributo volume (em porcentagem) foi representado pelo diâmetro, no qual quanto maior o diâmetro, maior a porcentagem de turistas com a mesma origem, e o inverso também é verdadeiro.

Para o cálculo das distâncias, primeiramente foi identificado com a ferramenta de geometria de vetores o centroide de cada Unidade da Federação (UF) com comentários, resultando no ponto de origem. A opção pelo uso de um centroide considerou que os dados dos comentários agrupam turistas de diversos municípios e dessa forma foi possível obter a distância média de cada UF para o PEJ. Após esse processamento com o plugin Oursins foi calculada a distância em quilômetros de cada centroide para o ponto de referência do PEJ.

Para verificar o nível de renda da demanda, visto que este dado não consta nos documentos consultados, adotou-se o rendimento médio domiciliar per capita. Segundo IBGE (2016) e (OECD, 2019) este indicador corresponde à média das rendas domiciliares per capita das pessoas residentes em determinado espaço geográfico, no ano considerado. No caso desta pesquisa, o espaço geográfico corresponde ao estado da federação no caso do turismo nacional e o país no caso do turismo internacional. Considera-se ainda como renda domiciliar per capita a soma dos rendimentos mensais dos moradores do domicílio, dividida pelo número de seus moradores.

No que se refere a distribuição espacial da população no território, especialmente no que diz respeito a residência em áreas urbanas ou rurais, adotou-se para esta pesquisa a taxa de população urbana total, que de acordo com o IBGE (2016) envolve a seguinte definição: a contagem da população residente na área urbana, é construída a partir do espaço geográfico considerado área urbana. Área urbana é constituída pela área interna ao perímetro urbano de uma cidade ou vila, definida por lei municipal.

Para as cidades ou vilas onde não existe legislação que regulamente essas áreas, deve-se estabelecer um perímetro urbano para fins da coleta censitária, cujos limites devem ser aprovados pelo prefeito local. Para o presente estudo, a fim de possibilitar a comparação de dados entre diversos estados, adotou-se a proporção de pessoas que residem no meio urbano em relação a população total do estado. Nesse sentido, tomou-se a população residente na área urbana levantada pelo IBGE, dividindo-se pelo total da 
população do mesmo estado, obtendo-se assim o percentual de pessoas de determinada unidade da federação que residem no espaço urbano.

Da mesma forma, visto não haver a indicação do nível escolar dos turistas no TripAdvisor, adotou-se para o presente estudo o conceito de média de anos de estudo, que segundo o IBGE (2016) consiste em considerar a soma total de anos de estudo das pessoas de uma determinada idade dividido pelo total de pessoas do mesmo grupo etário. Dessa forma, entende-se que se em determinado estado as pessoas frequentaram quatro anos de escola em média, apenas cursaram até o nível básico. Por outro lado, ao cursarem mais de dez anos em média, boa parte concluiu o ensino médio e cursou o nível superior. Nesse sentido, quanto maior a média de anos de estudo maior é o nível educacional de determinada região ou estado.

Outra preocupação da investigação foi dimensionar a distância entre o local emissor da demanda de turistas e o destino receptor, Jalapão já que na atividade turística as distâncias são consideradas como uma importante variável para o destino, de maneira que os países mais próximos são aqueles que realizam viagens entre si, (RABAHY, 2020). O mesmo ocorre na esfera estadual e regional, o que não difere no Jalapão, ou seja, os municípios mais próximos do Jalapão são um forte indutor de turistas.

Os dados nacionais foram coletados no banco de dados do IBGE, assim dados sobre rendimento nominal domiciliar per capita e dados sobre média de anos de escolaridade foram retirados da Pesquisa Nacional por Amostra de Domicílios Contínua de 2018 (IBGE, 2018). Dados sobre distribuição da população urbana foram retirados do Censo Demográfico de 2010 (IBGE, 2010). Os dados internacionais foram consultados nos sites da Organisation for Economic Co-operation and Development - OECD, para dados sobre rendimento nominal mensal domiciliar per capita (OECD, 2019); do Department of Economic and Social Affairs (ONU), para dados sobre distribuição da população urbana (ONU, 2018); e do DB-City, para média de anos de escolaridade (DB-CITY, 2015).

Visto que o estudo está baseado nos comentários dos turistas postados na plataforma TripAdvisor, considera-se o número de comentários dos turistas como próxi da origem do fluxo turístico. Essa opção foi adotada, considerando-se o conceito de turista real consumidor (BOULLÓN, 2002), inferindo-se que os indivíduos que postaram suas impressões na internet realmente visitaram o PEJ. Nesse sentido, os comentários no TripAdvisor foram considerados como amostra da demanda turística do PEJ. Esse procedimento já foi utilizado em estudos de Castro e Gândara (2019) e Castro (2020) ao estudar destinos turísticos no Paraná. Os dados foram sistematizados de forma que considerasse o estado de origem do turista, a fim de que as demais variáveis pudessem ser mensuradas. 


\section{Resultados}

\section{O estudo da demanda turística para o Jalapão}

A demanda turística para o Jalapão será caracterizada a partir das informações publicizadas dos turistas que realizaram comentários na plataforma TripAdvisor. Avaliamos os atrativos mais famosos e que mais receberam comentários de turistas: Cachoeira da Formiga, Cachoeira da Velha, Dunas, Fervedouro do Ceiça, Povoado de Mumbuca e Serra do Espírito Santo. Foram coletados 2.104 comentários, sendo distribuídos entre os atrativos conforme a Tabela 1. Os atrativos com mais comentários foram Cachoeira da Formiga com 690 (33\%), Dunas com 504 (24\%) e Cachoeira da Velha com 424 (20\%). Já o Povoado de Mumbuca foi o menos citado com 116 comentários (5\%). Os comentários citaram que as visitas ocorreram entre 2012 e agosto de 2019.

Tabela 1: Número de comentários relacionados aos atrativos do PEJ.

Tabela 1: Number of comments related to the PEJ's attractions.

\begin{tabular}{|l|c|c|}
\hline \multicolumn{1}{|c|}{ Atrativo } & Número de comentários & Proporção \\
\hline Cachoeira da Formiga & 690 & $33 \%$ \\
\hline Cachoeira da Velha & 424 & $20 \%$ \\
\hline Dunas do Jalapão & 504 & $24 \%$ \\
\hline Fervedouro do Ceiça & 232 & $11 \%$ \\
\hline Serra do Espírito Santo & 138 & $7 \%$ \\
\hline Povoado do Mumbuca & 116 & $5 \%$ \\
\hline Total & 2104 & $100 \%$ \\
\hline
\end{tabular}

Fonte: Elaborado pelos autores com dados de TripAdvisor (2019).

Source: Elaborated by authors based on TripAdvisor data (2019).

\section{Quantidade de Comentários}

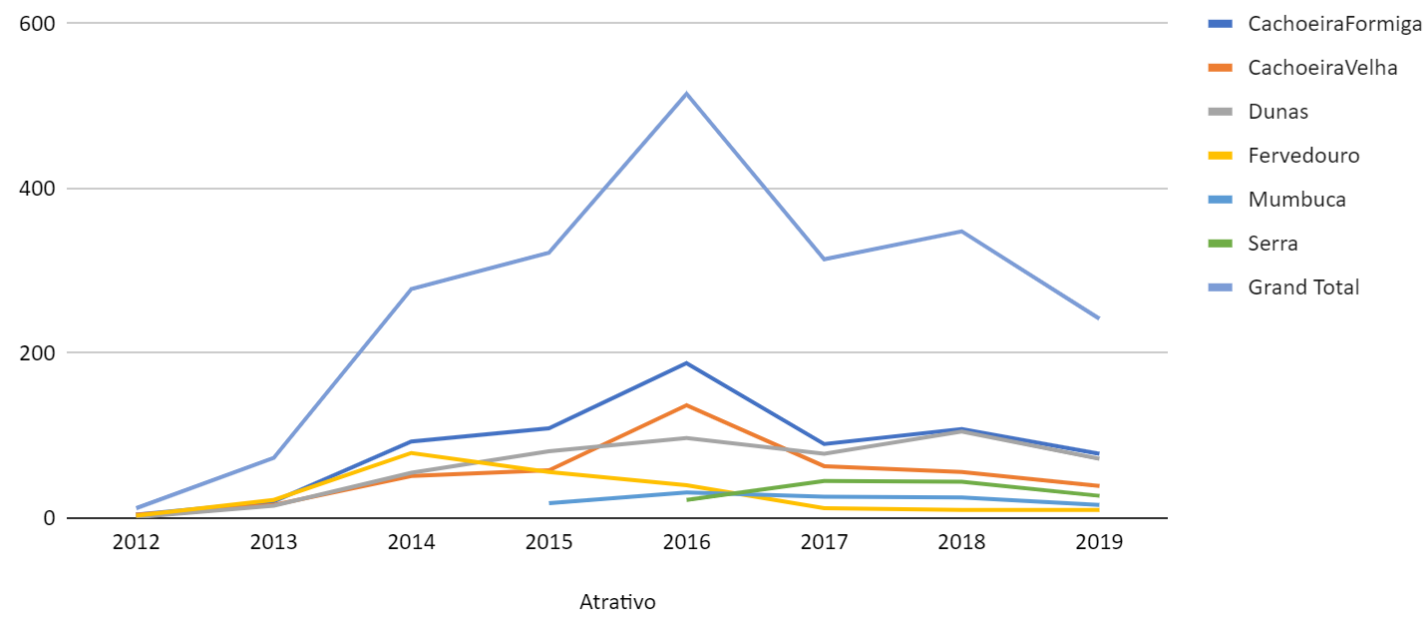

Figura 1: Distribuição anual da quantidade de comentários sobre o PEJ.

Figure 1: Annual distribution of the comments number about PEJ.

Fonte: Elaborado pelos autores com dados do TripAdvisor (2019).

Source: Elaborated by the authors based on TripAdvisor data(2019) 
A evolução anual do número de comentários é observada na Figura 1. Cada atrativo visitado é representado por uma linha com cor diferente de acordo com a legenda. Também existe uma linha (Grand Total) que representa o acumulado dos comentários dos atrativos. Os anos 2012, data do primeiro comentário, e o ano 2019 estão no eixo horizontal. O pico de comentários de uma maneira geral ocorreu no ano de 2016, sendo menores em 2017 e 2018. O ano de 2019 não está completo, visto que as informações foram colhidas até o mês de agosto de 2019.

Os atrativos Cachoeira da Formiga, Dunas e Cachoeira da Velha apresentam comentários desde o ano de 2012. Já o atrativo Povoado de Mumbuca apresentou os primeiros comentários em 2015 e a Serra do Espírito Santo apenas em 2016. A Cachoeira do Formiga dominou a maioria dos anos como o atrativo mais comentado, seguido pelas Dunas. Já o Fervedouro foi o mais comentado até 2014 quando perdeu representatividade até tornar-se o com o menor número de comentários a partir de 2017.

Nas seções seguintes são apresentadas as análises referentes às demandas turísticas nacionais e internacionais para o Jalapão, considerando 1759 comentários dos 2104 inicialmente definidos. Foi necessário desconsiderar 343 comentários pois não foi possível identificar suas origens.

\section{Demanda Nacional}

A demanda nacional para o PEJ foi registrada em 1708 comentários no Tripadvisor, representando $97,10 \%$ dos comentários com identificação de localidade. A Tabela 2 apresenta a distribuição do número de comentários por estado e as suas características de distância, anos de escolaridade, rendimento e população urbana. Os estados estão ordenados pela participação no número de comentários. A escolaridade, rendimento e urbanização estão também representadas por grade de cores onde a cor verde representa valores maiores e vermelho os menores.

Os dados da Tabela 2 também foram representados nos mapas da Figura 2 de forma geográfica para facilitar a visualização espacial dos itens avaliados. O primeiro mapa representa a distância e o número de comentários pelos tamanhos dos círculos dentro dos estados. Os outros três representam escolaridade, urbanização e renda por estado, e as cores mais escuras representam os maiores valores para esses índices. 
Tabela 2: Número de comentários, distância, anos de escolaridade, rendimento per capita e índice de população urbana dos estados com visitantes ao Jalapão.

Table 2: Number of comments, distance, years of schooling, per capita income and urban population index of the states with visitors to Jalapão.

\begin{tabular}{|c|c|c|c|c|c|c|}
\hline Estado & $\begin{array}{r}\text { Nú } \\
\text { Perce } \\
\text { Com }\end{array}$ & $\begin{array}{l}\text { nero e } \\
\text { ntual de } \\
\text { entários } \\
\text { (a) }\end{array}$ & $\begin{array}{c}\text { Distância } \\
(\mathrm{km})\end{array}$ & $\begin{array}{c}\text { Anos de } \\
\text { Escolaridade } \\
\text { (b) }\end{array}$ & $\begin{array}{c}\text { Rendimento } \\
\text { (R\$) } \\
\text { (c) }\end{array}$ & $\begin{array}{c}\text { População } \\
\text { Urbana } \\
\text { (d) }\end{array}$ \\
\hline São Paulo & 658 & $38.52 \%$ & 1.342 & 11.1 & 1898 & $95.0 \%$ \\
\hline Rio de Janeiro & 304 & $17.80 \%$ & 1.389 & 10.2 & 1689 & $96.0 \%$ \\
\hline Tocantins & 125 & $7.32 \%$ & 172 & 9.8 & 1045 & $78.0 \%$ \\
\hline Minas Gerais & 116 & $6.79 \%$ & 932 & 10.3 & 1322 & $85.0 \%$ \\
\hline Distrito Federal & 110 & $6.44 \%$ & 618 & 11.6 & 2460 & $96.0 \%$ \\
\hline Paraná & 78 & $4.57 \%$ & 1.669 & 10.9 & 1607 & $85.0 \%$ \\
\hline Santa Catarina & 61 & $3.57 \%$ & 1.918 & 11.6 & 1660 & $84.0 \%$ \\
\hline Bahia & 47 & $2.75 \%$ & 601 & 9.5 & 841 & $72.0 \%$ \\
\hline Rio Grande do Sul & 38 & $2.22 \%$ & 2.255 & 9.6 & 956 & $85.0 \%$ \\
\hline Goiás & 36 & $2.11 \%$ & 708 & 10.4 & 1323 & $90.0 \%$ \\
\hline Ceará & 23 & $1.35 \%$ & 975 & 10.3 & 855 & $75.0 \%$ \\
\hline Pará & 15 & $0.88 \%$ & 985 & 9.1 & 863 & $68.0 \%$ \\
\hline Esnírito Santo & 13 & $0.76 \%$ & 1.219 & 10.6 & 12.95 & $83.0 \%$ \\
\hline Maranhão & 13 & $0.76 \%$ & 601 & 9.8 & 605 & $63.0 \%$ \\
\hline Pernambuco & 13 & $0.76 \%$ & 987 & 9.3 & 871 & $80.0 \%$ \\
\hline Rio Grande do Norte & 13 & $0.76 \%$ & 1.216 & 11.0 & 1705 & $77.0 \%$ \\
\hline Mato Grosso & 10 & $0.59 \%$ & 1.040 & 10.8 & 1386 & $81.0 \%$ \\
\hline Paraíba & 9 & $0.53 \%$ & 1.147 & 9.6 & 898 & $75.0 \%$ \\
\hline Amazonas & 7 & $0.41 \%$ & 2.088 & 9.0 & 7991 & $79.0 \%$ \\
\hline Mato Grosso do Sul & 7 & $0.41 \%$ & 1.409 & 10.0 & 1439 & $85.0 \%$ \\
\hline Seraine & 5 & $0.29 \%$ & 1.021 & 9.1 & 906 & $73.0 \%$ \\
\hline Rondônia & 4 & $0.23 \%$ & 1.761 & 10.2 & 1113 & $73.0 \%$ \\
\hline Alaaoas & 3 & $0.18 \%$ & 1.115 & 9.1 & 714 & $73.0 \%$ \\
\hline Acre & 0 & $0,00 \%$ & 0 & 9,0 & 909 & $72,6 \%$ \\
\hline Amapá & 0 & $0,00 \%$ & 0 & 9,6 & 857 & $89,0 \%$ \\
\hline Piauí & 0 & $0,00 \%$ & 0 & 9,6 & 817 & $65,0 \%$ \\
\hline Roraima & 0 & $0,00 \%$ & 0 & 10,1 & 1204 & $76,0 \%$ \\
\hline
\end{tabular}

Fonte: Elaborado pelos autores a partir de dados de (a) TripAdvisor (2019); (b) (c)IBGE (2018); (d) IBGE (2010).

Source: Elaborated by the authors based on (a) TripAdvisor (2019); (b) and (c) IBGE (2018); and (d) IBGE (2010). 


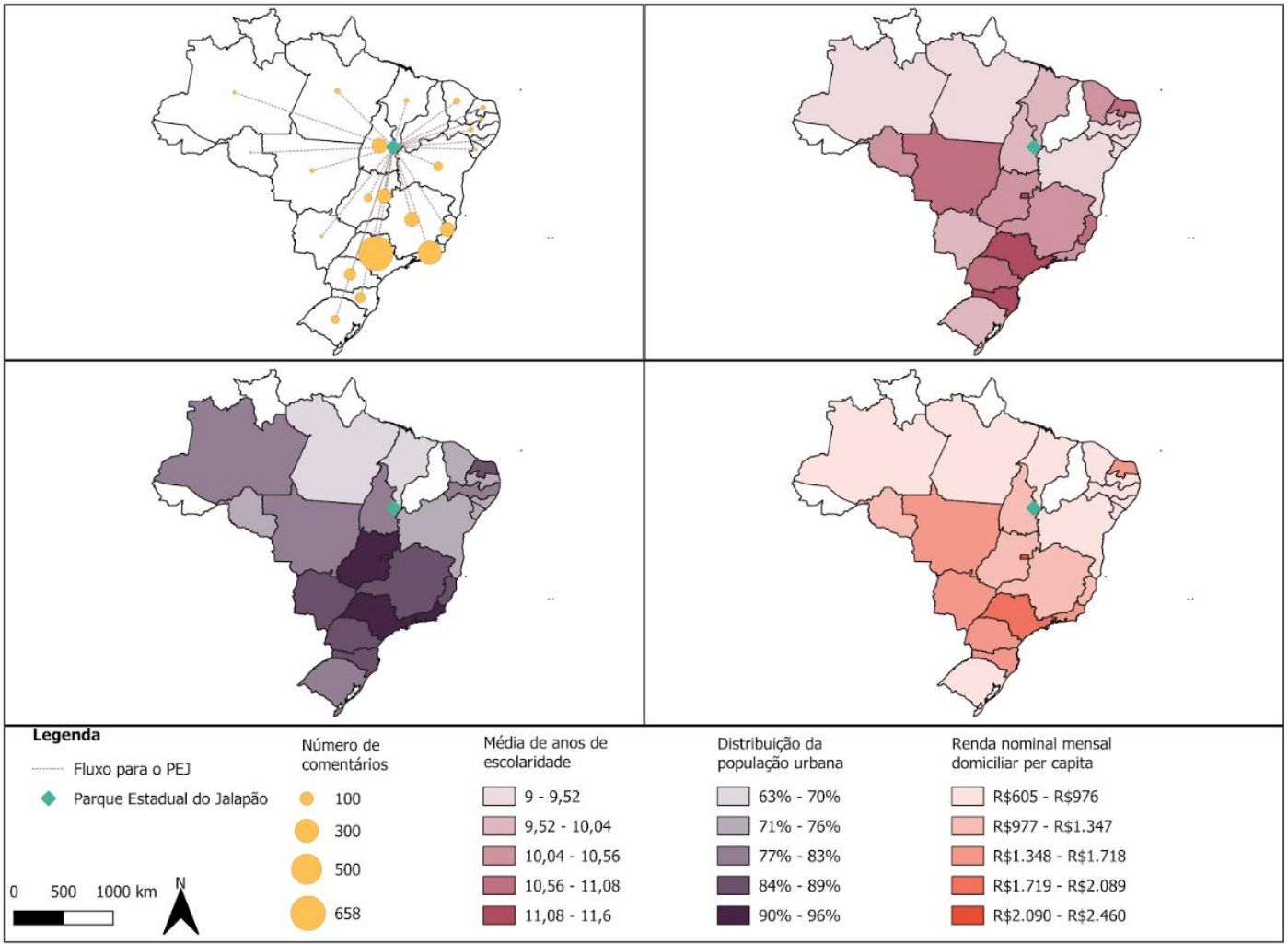

Figura 2: Localização de procedência da demanda nacional para o Jalapão.

Figure 2: Origin location of national demand for Jalapão

Fonte: Elaborado pelos autores a partir de TripAdvisor(2019) e IBGE (2010; 2018).

Source: Elaborated by the authors based on TripAdvisor(2019) and IBGE $(2010 ; 2018)$.

São Paulo é o estado que mais envia turistas ao Jalapão, são 658 comentários. Em segundo lugar o Rio de Janeiro com 304 comentários; Tocantins aparece logo em seguida com 125 comentários; Minas Gerais contribuiu com 116 comentários. Na Tabela 2 pode-se observar que em torno de $70 \%$ dos turistas são originários destes quatro estados. Nota-se que são estados com grande concentração da população brasileira, a exceção do Tocantins. Os dados colhidos junto ao tripadvisor são similares aos obtidos em pesquisa direta realizada pela Agência do Desenvolvimento do Turismo, da Cultura e Economia Criativa no ano de 2017 (TO, 2017).

A variável distância também foi considerada, temos que São Paulo dista 1.342 km do Jalapão, Rio de Janeiro 1.389 km, Minas Gerais 932 km e Tocantins $172 \mathrm{~km}$. Estudos sobre distância relacionados como atração de demanda são bastante evidenciados como variável de atração de turistas. No exemplo investigado tivemos como resultado que São Paulo é o estado que, fora o próprio Tocantins, emite mais turistas para o Jalapão, depois está o Rio de Janeiro, estado mais distante dos quatro eleitos para análise, visto que são os maiores emissores para o destino, seguido de Minas Gerais, com $932 \mathrm{~km}$. Esses dados colocam o destino Jalapão como um destino nacional, visto que mais da metade dos seus visitantes é originário de locais emissores dentro do país e distantes acima de $500 \mathrm{~km}$ do destino (BOULLÓN, 2002). 
Estudos realizados por Rabahy (2020) e Rabahy, Silva e Vassallo (2008) são enfáticos em considerar que a distância é uma condição importante para caracterizar a demanda, os estudos da demanda nacional oferecem dados similares aos estudos de demanda internacional. Com a moeda nacional valorizada há estímulo de saída de brasileiros para fora do país, o mesmo ocorre com o turismo doméstico, onde o movimento de viagens é mais ativo em localidades fronteiriças, mas são afetados também pelas variações de renda.

Segundo a literatura, o perfil do turista que se dirige para destinos de ecoturismo possui maior nível educacional. Para checar se esse fato se repete para o destino Jalapão, levantou-se as informações relacionadas com esta variável para os estados que se caracterizaram como emissores de turistas. Como pode ser visto na Figura 2, pelo gradiente de cores os estados que apresentam o maior número de avaliações também apresentam os maiores índices de escolaridade medidos pelos anos de permanência na escola, todos acima de 10 anos. $\mathrm{Na}$ Tabela 1, estes dados são apresentados em forma de percentual, São Paulo, Rio de Janeiro e Minas Gerais estão entre os estados que mais emitem turistas e com população que frequenta em média mais de 10 anos de escola. Dentre os quatro primeiros emissores de turistas, apenas Tocantins fica abaixo dos 10 anos, porém, muito próximo com 9,8 anos.

No que diz respeito ao rendimento médio mensal, pode-se verificar na Figura 2 que os estados que mais emitem turistas ao Jalapão também possuem rendas mais elevadas, não na mesma ordem. A renda per capita mensal da demanda se comporta da seguinte maneira conforme pode ser visto na Tabela 2: $R \$ 1.898$ é a média de renda do turista procedente de São Paulo; $R \$ 1.689$ é a renda do turista proveniente do Rio de Janeiro; Minas Gerais $R \$ 1.322$ e Tocantins $R \$ 1.789$.

Corroborando com os dados, verifica-se que em termos regionais, os rendimentos médios mensais das pessoas de 10 anos ou mais de idade, com rendimento, das Regiões Centro-Oeste e Sudeste, ficaram próximos e foram os mais elevados, vindo em seguida o da Região Sul. O rendimento da Região Nordeste foi o menor, representando 56,7\% daquele auferido na Região Centro-Oeste, enquanto o segundo mais baixo, que foi o da Região Norte, abrange 67,3\% (IBGE, 2010).

Os dados sobre as grandes concentrações urbanas do Brasil foram obtidos pelo IBGE (2010) no estudo chamado Arranjos Populacionais e Concentrações Urbanas do Brasil. $O$ instituto identificou 26 "grandes concentrações urbanas" no Brasil. Em termos de concentração populacional, as grandes concentrações urbanas representam as faixas mais populosas, seguidas pelas "médias concentrações urbanas" (municípios isolados e arranjos populacionais entre 100 mil e 750 mil habitantes). Dos 294 arranjos identificados no censo do IBGE de 2010, o Brasil possui 187 com população inferior a 100 mil habitantes, sendo a maioria, portanto, considerada como de concentração populacional baixa.

Para efeito de análise o recorte da pesquisa considerou apenas os quatros Estados de maior emissão de turista para o Jalapão, que são: São 
Paulo com uma concentração populacional de mais de vinte e hum milhão e seiscentos mil habitantes (21.656.301); Rio de Janeiro com mais de doze milhões e setecentos mil (12.777.959); e Minas Gerais com cinco milhões e cem mil habitantes (5.176.131). O estado do Tocantins apresenta uma concentração urbana não tão alta $(78 \%)$ e por isso não é evidenciado no estudo do IBGE. A população do Tocantins foi estimada em mais de hum milhão e quinhentos mil habitantes (1.572.866) em 139 municípios. A estimativa com o total de habitantes dos estados e dos municípios se refere a $1^{\circ}$ de julho de 2019 e foi publicada no Diário Oficial da União.

Em síntese pode-se considerar que as variáveis renda, população urbana, taxa de escolaridade são importantes para a caracterização da demanda turística de uma forma geral. Entretanto, o destino Jalapão, pelas características inerentes ao território, por ser um destino relativamente novo e em formação, pela dificuldade de acesso, de vôos diretos e limitação de serviços, favorece que a maior parte dos turistas sejam provenientes dos municípios limítrofes, conforme já evidenciado por Rabahy (2003).

Nesta seção apresentaram-se os dados correspondentes a demanda nacional e adiante, explora-se melhor o comportamento da demanda internacional.

\section{Demanda Internacional}

A demanda internacional para o PEJ foi registrada em 51 comentários no Tripadvisor, representando $2,90 \%$ dos comentários com identificação de localidade, um índice pequeno para análises mais robustas e complexas. A Tabela 3 apresenta o número de comentários por país, a distância até o Jalapão, a escolaridade, o rendimento e a população urbana (urbanização).

Os países que mais fazem referência no TripAdvisor são por ordem da maior frequência para a menor: Espanha com 7 comentários, Reino Unido com 6 e Austrália também com 6, Estados Unidos com 5; e Argentina, França e Itália, todos com 4. A renda per capita por domicílio nesses países, em ordem decrescente é a seguinte: EUA com U\$ 3.774, Argentina com U\$ 3.766, Austrália com U\$ 2.730, França com U\$2.609, Reino Unido com U\$ 2.348, Itália U\$2.216 e Espanha com U\$2.000. Destaca-se que o país com a menor renda teve a maior participação.

Os países com maior índice turistas provenientes dos países emissores de turista ao Jalapão, $87 \%$ a $92 \%$ são provenientes de países com alta concentração urbana. Argentina $92 \%$ da população reside em áreas urbanas; $91 \%$ da população que mora na Holanda também reside em áreas urbanizadas. Podemos considerar que percentualmente a Argentina é o país com mais visitação ao Jalapão e que também é na Argentina (92\%) da população, que apresenta a maior concentração de habitantes em áreas urbanas. A média de anos de escolaridade dos turistas internacionais que visitaram o Jalapão está entre 12,36 a 13,30 anos para os locais de origem com o maior número de turistas que realizaram os comentários na plataforma, após a viagem. 
Tabela 3: Número de comentários, anos de escolaridade, rendimento e índice de população urbana dos países com visitantes ao Jalapão.

Table 3: Number of comments, years of schooling, income and urban population index of countries with visitors to Jalapão.

\begin{tabular}{|c|c|c|c|c|c|c|}
\hline País & $\begin{array}{c}\text { Número e } \\
\text { Percentual de } \\
\text { Comentários } \\
\text { (a) }\end{array}$ & $\begin{array}{c}\text { Distância } \\
(\mathbf{K m})\end{array}$ & $\begin{array}{c}\text { Anos de } \\
\text { Escolaridade } \\
\text { (b) }\end{array}$ & $\begin{array}{c}\text { Rendimento } \\
\text { (US\$) } \\
\text { (c) }\end{array}$ & $\begin{array}{c}\text { População } \\
\text { Urbana } \\
\text { (d) }\end{array}$ \\
\hline Espanha & 7 & $13,73 \%$ & 7.152 & 9,8 & 2000 & $80,6 \%$ \\
\hline Austrália & 6 & $11,76 \%$ & 14.689 & 13,2 & 2730 & $86,1 \%$ \\
\hline Reino Unido & 6 & $11,76 \%$ & 8.174 & 13,3 & 2348 & $83,7 \%$ \\
\hline Estados Unidos & 5 & $9,80 \%$ & 6.280 & 13,2 & 3774 & $82,5 \%$ \\
\hline Argentina & 4 & $7,84 \%$ & 2.946 & 9,8 & 3766 & $92,0 \%$ \\
\hline França & 4 & $7,84 \%$ & 8.129 & 11,6 & 2609 & $80,7 \%$ \\
\hline Itália & 4 & $7,84 \%$ & 8.354 & 10,9 & 2216 & $70,7 \%$ \\
\hline Alemanha & 3 & $5,88 \%$ & 8.991 & 13,2 & 2858 & $77,4 \%$ \\
\hline México & 3 & $5,88 \%$ & 7.032 & 8,6 & 2550 & $80,4 \%$ \\
\hline Nova Zelândia & 3 & $5,88 \%$ & 12.888 & 12,5 & 2800 & $86,6 \%$ \\
\hline Holanda & 2 & $3,92 \%$ & 8.505 & 11,9 & 2444 & $91,9 \%$ \\
\hline Chile & 1 & $1,96 \%$ & 3.543 & 9,9 & 2800 & $87,6 \%$ \\
\hline Noruega & 1 & $1,96 \%$ & 9.287 & 12,7 & 2977 & $82,6 \%$ \\
\hline Panamá & 1 & $1,96 \%$ & 4.209 & 9,9 & 5904 & $68,1 \%$ \\
\hline Portugal & 1 & $1,96 \%$ & 6.684 & 8,9 & 1767 & $65,8 \%$ \\
\hline
\end{tabular}

Fonte: Elaborado pelos autores com dados de (a) TripAdvisor (2019), (b) DB-City (2015), (c) OECD (2019), e (d) ONU (2018).

Source: Elaborated by the authors with data from (a) TripAdvisor (2019), (b) DB-City (2015), (c) OECD (2019), and (d) Department of Economic and Social Affairs (2018).

Os gastos dos brasileiros no exterior apresentam íntima relação com a renda e, em especial, com as flutuações de câmbio. No documento "Anuário Estatístico de Turismo 2020, ano base 2019" (MTUR, 2020) há um vasto estudo dos dados de entrada e saída de turistas. No que diz respeito ao Tocantins as estatísticas desconsideram o Estado, por não ter uma representação significativa, entrando nas estatísticas de "Outras unidades da Federação". Importante também indicar que muitos turistas estrangeiros que chegam ao Tocantins entram no país a partir de São Paulo, maior centro receptor de turistas internacionais e centro de distribuição dos destinos domésticos.

Nos estudos sobre demanda, Rabahy (op. cit, 2019) acredita que o Brasil apresenta condições particulares de sustentação do crescimento de seu turismo a partir do fortalecimento do mercado interno. Ainda que não se justifique como foco primário para o desenvolvimento da atividade no país, o turismo internacional acaba se beneficiando da estrutura desenvolvida e sustentada pelo turismo doméstico.

A demanda internacional para o Jalapão é baixa, mas é importante conhecer esse fluxo turístico que vai se acentuando. A Figura 3 apresenta os números de comentários de forma espacial em um mapa mundial, indicando 
a distância e o número de comentários, este representado pelo tamanho dos círculos dentro dos países. Pode-se identificar a pequena participação dos turistas estrangeiros pelo quantitativo de comentários. Em outro documento produzido pelo Estado do Tocantins "Análise do Perfil da Demanda Região Turística Encantos do Jalapão" constata-se que dos 365 entrevistados da pesquisa realizada no ano de 2015 para o Jalapão 99\% são provenientes do próprio país (TO, 2017). Entretanto, neste trabalho constatamos a tendência de alta no turismo internacional ao Jalapão, pois identificamos 2,9\% de comentários internacionais.

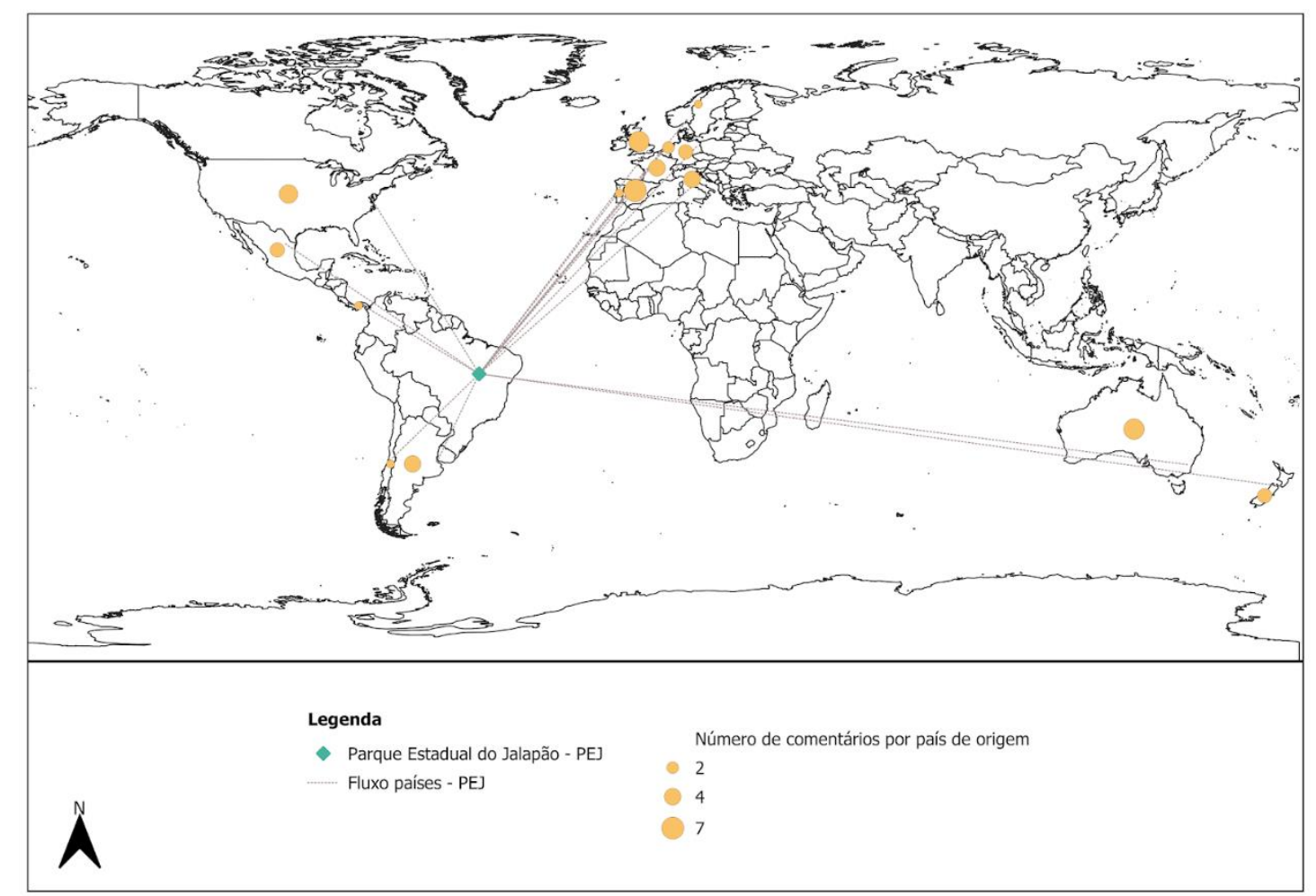

Figura 3: Localização de procedência da demanda internacional para o Jalapão.

Figure 3: Origin location of international demand for Jalapão.

Fonte: Elaborado pelos autores a partir de TripAdvisor(2019).

Source: Elaborated by the authors based on TripAdvisor(2019).

\section{Considerações finais}

A pesquisa teve o objetivo de analisar o mercado turístico para 0 Jalapão, tomando como objeto a demanda nacional e internacional que realizaram comentários na Plataforma TripAdvisor entre os anos de 2012 e 2019.

Partimos da premissa de que quanto maior o contingente populacional dos Estados ou países maior é a probabilidade de buscarem o destino Jalapão, seguindo os pressupostos já evidenciados na literatura consultada.

Para o tratamento de dados com o fito de concretizar a investigação foram utilizados os recursos da etnografia e de base de dados especificamente trabalhados, extraídos do IBGE, principalmente, além de 
apoio no geoprocessamento para a construção de mapas para a representação da origem dos comentários sobre o destino turístico Jalapão provenientes da plataforma Tripadvisor.

O estudo teórico fez menção às principais categorias de análise na composição do produto turístico: a demanda e a oferta, além de incursões nos conceitos de população e concentração urbana, turismo e turismo ecológico e suas variantes, demanda turística e aspectos da evolução do turismo de massa para o turismo ecológico.

As variáveis selecionadas para a investigação, que são o local de procedência do turista, o nível de escolaridade e da renda e a concentração urbana com o apoio na literatura e na pesquisa documental deu condições para a comprovação da premissa de que os turistas que vão ao Jalapão são provenientes de cidades com maior número de população urbana e foram determinadas por estudos relacionados a economia do turismo já discutidos na seção do referencial teórico deste artigo.

Podemos considerar a comprovação da premissa levantada, visto que, constatou-se por meio das variáveis estudadas que o tráfego mais representativo advinha de turistas provenientes das cidades mais urbanizadas do Brasil. No estudo da demanda nacional a procedência mais importante foi proveniente de São Paulo, Rio de Janeiro e do próprio Tocantins, seguido por Minas Gerais. Com isso, atendeu-se o primeiro objetivo do estudo que consistiu em verificar os principais locais de origem dos turistas para o Jalapão. Assim, observa-se no estudo o já indicado na literatura para outros destinos, os espaços urbanos de maior contingente populacional tendem a emitir maior número de turistas para o Jalapão, no caso destino de ecoturismo ou turismo de aventura. Esses dados são consistentes com o discutido por Martine (2007) quanto a tendência de maior concentração humana nas cidades e que os principais emissores são as cidades que possuem maior população e renda conforme evidenciado por Castro (2020).

O segundo objetivo específico consistia em verificar as características socioeconômicas dos turistas identificados na plataforma digital. Nesse caso, outros dados estudados reforçam que a caracterização da demanda é o nível de escolaridade e renda dos turistas que visitaram o Jalapão no período de recorte da pesquisa (2012-2019). Todos esses levantamentos corroboram para a comprovação de que o indicador local de procedência para o destino ecológico Jalapão corresponde a regiões com renda e nível escolar alto, coadunando com os fatores evidenciados pela literatura descrita no referencial teórico deste artigo.

Finalmente, buscou-se analisar as características demográficas dos locais de origem dos turistas à luz dos conceitos de demanda turística para destinos ecológicos. Nesse caso, verificou-se que os maiores emissores são os que possuem concentração urbana, renda e escolaridade altas. Nesse sentido, responde-se a questão proposta de que a urbanidade é responsável pela emissão de turistas para espaços com apelo ecológico, caso do Jalapão, no cerrado do Tocantins. 
Os objetivos propostos para o estudo foram alcançados e a utilização dos dados da plataforma TripAdvisor se mostraram consistentes neste caso para a análise da demanda ao destino turístico Jalapão. As proporções obtidas coincidiram com os dados de outras pesquisas empíricas já realizadas para o mesmo destino. Entretanto, por ser um estudo exploratório e descritivo, deve ser aceito com reservas, demandando mais estudos que venham sustentar seus achados. Nesse caso, sugere-se replicar o estudo em outros destinos ecológicos a fim de aprofundar conhecimentos e aperfeiçoar os instrumentos utilizados para análise da demanda de destinos turísticos.

\section{Referências}

ABETA, Associação Brasileira das Empresas de Ecoturismo e Turismo de Aventura. Perfil do Turista de Aventura e do Ecoturista no Brasil. Ministério do Turismo, 2010, 96p.

BENI, M. C. Turismo: da economia de serviços à economia da experiência. Revista Turismo - Visão e Ação, v. 6, n.3, p. 296-306, 2004.

BENI, M. C. Análise estrutural do turismo. São Paulo: SENAC, 2019.

BOULLÓN, R. Planejamento do espaço turístico. Bauru: EDUSC, 2002.

CASTRO, F. J. G. Fatores explicativos da oferta e da demanda dos destinos turísticos paranaenses, 2020. 102 f. Dissertação (Mestrado em Turismo) Departamento de Turismo - Universidade Federal do Paraná, Curitiba, 2020.

CASTRO, F. J. G.; GÂNDARA, J.M. A regionalização do turismo no Estado do Paraná sob a perspectiva do marketing. Marketing \& Tourism Review, v. 4, n. 1, 2019.

COELHO, A.; RIBEIRO, L. A economia da experiência. Observatório de Inovação do Turismo, v. 2, n.1, 1-3, 2007.

CRUZ, R.C.A. Políticas públicas de turismo no Brasil: território usado, território negligenciado. Geosul, v.20, n.40, 2005.

DANTAS, L.M.R; PIRES, P.S. Versões e Contradições do Turismo de Aventura: reflexões sobre as atividades de aventura e sobre o turista. Turismo e Sociedade, v. 8, n. 2, p. 276-300, maio-agosto de 2015.

DB-CITY. Média de anos de escolaridade por país. 2015. Disponível em: https://pt.db-city.com/Pa\%C3\%ADs--M\%C3\%A9dia-de-anos-de-escolaridade Acesso em 10 de junho de 2020.

DUTRA, V.C.; AQUINO, A.R. Aplicação e análise da pressão turística como indicador ambiental no Parque Estadual do Jalapão (TO). Revista Brasileira de Ecoturismo, v.11, n.3, 2018.

FERNANDES, D. L., SCHOAB, V. A., LAZANHA, D. A.; MAGANHOTTO, R. F. O compartilhamento das experiências vivenciadas na RPPN Ninho do Corvo, Prudentópolis, no TripAdvisor e sua classificação nas esferas da Economia da Experiência. Revista de Turismo Contemporâneo-RTC. v .8, n.1, p. 127-148, 2020. 
GUISSONI, R., ALENCAR, D. G.; GÂNDARA, J. M. O turismo de experiência no Paraná-Brasil: uma análise sobre os turistas que procuram por experiências em negócios, meio urbano e esportes. Turismo e Desenvolvimento, n. 32, p. 235-253, 2019.

HIRATA, F; BRAGA, D. C. Demanda turística e estudo sobre motivação. Boa Vista, Editora da UFRR, 2017.

ICMBio, Instituto Chico Mendes de Conservação da Biodiversidade. Atlas do Corredor Ecológico da Região do Jalapão. v.2, 2013. Disponível em: https://www.icmbio.gov.br/projetojalapao/images/stories/atlas/AtlasJica 2013 COMPLETO.pdf Acesso em 10 de junho de 2020.

ICMBio, Instituto Chico Mendes de Conservação da Biodiversidade. Planos de Manejo. $2020 . \quad$ Disponível em: https://www.icmbio.gov.br/portal/unidadesdeconservacao/planos-de-manejo Acesso em 10 de junho de 2020.

IBGE, Instituto Brasileiro De Geografia E Estatística. Características da população e domicílios. 2010. Disponível em: https://biblioteca.ibge.gov.br/visualizacao/periodicos/93/cd 2010 caracteristi cas populacao domicilios.pdf. Acesso em 12 de junho de 2020.

IBGE, Instituto Brasileiro De Geografia E Estatística. Síntese de indicadores sociais: uma análise das condições de vida da população brasileira. Rio de Janeiro, n. 36, 146 p, 2016

IBGE, Instituto Brasileiro De Geografia E Estatística. Pesquisa Nacional por Amostra de Domicílios Contínua trimestral - PNAD Contínua, 2018. Disponível em: https://www.ibge.gov.br. Acesso em 10 de junho de 2020.

IVARS, J. A. Planificación turística de los espacios regionales en España. Madrid: Editorial Sintesis, 2003.

LACERDA, C. S.; LIMA, E. R; MARTINS, M. F. Sistema de indicadores de sustentabilidade para a atividade turística e suas contribuições. Revista Iberoamericana de Turismo, v.9, n.1, p. 114-132, 2019.

MANKIW, N. G. Introdução à economia: princípios de micro e macroeconomia. Rio de Janeiro: Editora Campus, 1999.

MARTINE, G. O lugar do espaço na equação população/meio ambiente. Revista Brasileira de Estudos de População, v. 4, 2007.

MTUR, Ministério Do Turismo. Ecoturismo: Orientações básicas. $2^{\underline{a}}$ ed, 2010 Disponível em: http://www.turismo.gov.br/sites/default/turismo/o ministerio/publicacoes/dow nloads publicacoes/Orientacoes Basicas Ecoturismo.pdf. Acesso 10 de Junho de 2020.

MTUR, Ministério Do Turismo. Estudo da Demanda Turística Internacional - Brasil - 2018, 2018. Disponível em: http://www.dadosefatos.turismo.gov.br/2016-02-04-11-54-03/demandatur\%C3\%ADsticainternacional/item/download/964 616b0e66c036db76857f828354967e04.ht ml Acesso 10 de Junho de 2020. 
MTUR, Ministério Do Turismo. Portal Dados e Fatos do Ministério do Turismo, $2020 \quad$ Disponível em: http://www.dadosefatos.turismo.gov.br/r/semin tur 4/arquivos 4 seminario/ GT14-13.pdf Acesso 10 de Junho de 2020.

MUNZERT, S.; RUBBA, C., MEIBNER, P.; NYHUIS, D. Automated data collection with R: A practical guide to web scraping and text mining. John Wiley.;amp; Sons, 2014.

OECD, Organização para a Cooperação e Desenvolvimento Econômico. OECD Better Life Index, 2019. Disponível em: http://www.oecdbetterlifeindex.org/pt/quesitos/income-pt/ Acesso 10 de Junho de 2020.

ONU, Organização das Nações Unidas. World Urbanization Prospects 2018, 2018. Disponível em: https://population.un.org/wup/Country-Profiles/ Acesso 10 de Junho de 2020.

RABAHY, W. Turismo e desenvolvimento: estudos econômicos e estatísticos no planejamento. Barueri, SP: Manole, 2003.

RABAHY, W. Análise e perspectivas do turismo no Brasil. Revista Brasileira de Pesquisa em Turismo, v.14, n.1, 2020.

RABAHY, W. A.; SILVA, J. C. D.; VASSALO, M. D. Relações determinantes sobre despesas e as receitas da conta de viagens internacionais do balanço de pagamentos brasileiro. Revista Turismo em Análise, v. 19, n 2, 2008.

SANTOS, M.L.; ALENCAR, D.G.; ANDRADE, A.; GÂNDARA, J.M.G. Tendências do consumidor em turismo: a oferta no Paraná (Brasil) para demandantes de experiências. Investigaciones Turísticas, n. 16, p.143164, 2018.

PINDYCK, R.; RUBINFELD, D. Microeconomia. São Paulo: Prentice Hall, 2002.

TRIPADVISOR, Plataforma de viagens. Disponível em https://www.tripadvisor.com.br/ Acesso em 15 de fevereiro de 2020.

TO, GOVERNO DO ESTADO DO TOCANTINS. Análise do perfil da demanda: Região Turística Encantos do Jalapão - 2017. Disponível em: https://central3.to.gov.br/arquivo/410723/ Acesso em 22 de maio de 2020.

TO, GOVERNO DO ESTADO DO TOCANTINS. Regiões Turísticas: Mateiros. 2020. Disponível em: https://turismo.to.gov.br/regioesturisticas/encantos-do-jalapao/principais-atrativos/mateiros/ Acesso em 17 de janeiro de 2020.

TO, GOVERNO DO ESTADO DO TOCANTINS. Plano de manejo do Parque Estadual do Jalapão - 2003. Disponível em: http://gesto.to.gov.br/site media/upload/gestao/documentos/Plano de Mane jo - PEJ - Encarte 2 - Planejamento.pdf Acesso em 22 de maio de 2020.

VALLS, J. F. Las claves del mercado turístico: como competir en el nuevo entorno. Bilbao: Ediciones Deusto, 1996.

VIEIRA, G. D.; SCALCO, R. F.; SILVEIRA, J. M.; SILVEIRA, C. E. Mercado e perfil do ecoturista de Diamantina (MG): um estudo introdutório. Revista Brasileira de Ecoturismo. v. 7, n. 3, ago-set. 2014. 
Maria de Fatima de Albuquerque Caracristi: Universidade Federal do Tocantins, Palmas, TO, Brasil.

E-mail:mariaf@uft.edu.br

Link para o currículo Lattes: http://lattes.cnpq.br/3939379569549416

José Elmar Feger: Universidade Federal do Paraná, Curitiba, PR, Brasil.

E-mail: elmar@ufpr.br

Link para o currículo Lattes: http://lattes.cnpq.br/8671782571748625

João Eugenio Marynowski: Universidade Federal do Paraná, Curitiba, PR, Brasil.

E-mail: jeugenio@ufpr.br

Link para o currículo Lattes: http://lattes.cnpq.br/3265921900792672

Sarah Marroni Minasi: Universidade do Vale do Itajaí, Balneário Camboriú, SC, Brasil.

E-mail: sarahminasi@gmail.com

Link para o currículo Lattes: http://lattes.cnpq.br/2545244942377567

Data de submissão: 20 de novembro de 2020

Data de recebimento de correções: 21 de dezembro de 2020

Data do aceite: 21 de dezembro de 2020

Avaliado anonimamente 